offered and made available to any other country that will take the side of democracy by standing up against Germany. This has been done, however, on the basis of friendship and engagement in a common venture, and that of itself may suggest that, as alternative to federal union, the British Commonwealth of Nations, united by common conventions and understandings about the position and the action of its members, not by virtue of common federal institutions, at least deserves consideration.

It is a mistake to insist too crudely that the choice is between federal union or a formal alliance, as Mr. Streit does, and to reject the latter as bad. It is at least possible that there is a third way, tentative and difficult, but in the end surer and wiser - the experimental way of finding and working out our common understandings and forging the appropriate instruments to serve common purposes. Already we have seen the chastening of nationalism in the British Commonwealth. Given the dynamic outlook and readiness to face change and try new methods, the consciousness of common ideals and traditions which lend Mr. Streit his own inspiration, the same spirit which has worked out effectively the relations between the United Kingdom and the
Dominions may work no less harmoniously and effectively between the United States and the British Empire.

To that task must be addressed not idealism alone but also the dispassionate spirit of scientific inquiry, ever advancing step by step as new experiments in co-operation are tried. To such experiments the moral appeal and the rapidly developing world situation give urgency, but it is only on the basis of ascertained facts that Great Britain and the United States can discharge adequately their inescapable responsibilities in peace or in war for the defence of freedom and their common heritage. Whether the first or final stage be union, partnership in some more or less organized form will be required to resolve the conflict between nationalism and trade, industry and culture, and make possible a reconstruction of the world on principles which transcend the national sovereignty that has plunged it into chaos. In such a partnership Great Britain and the United States may well once more attest the truth of Lowell's prophetic words of February 1861, and their manhood make a greater opportunity out of the great danger which they at present share.

\title{
FACT AND TRUTH
}

F ROM time to time there flare up echoes of the old controversy between science and religion; not, be it noted in any official form in the sense that leaders of either party take part, but individuals of deep convictions suddenly produce attacks, occasionally in print, which one had hoped were disposed of half a century ago. The fact that such attacks still occur is a reflection on men of science themselves, indicating that they have not yet succeeded in spreading the message of science so widely as they should have done ; though it may be in part due to singular obtuseness on the part of their hearers.

The ill-informed have in recent months frequently blamed science for the misuse that has been made of its gifts to mankind, for the developments of the means of waging modern warfare. With that aspect we have often dealt, and we need not go over the ground again. A particularly subtle form of attack on science, however, is to take the line that the facts of science actually have the impermasence of matter, which changes and fades continually, and to contrast them with the truths of religion, which are permanent. Science being based on facts, and the facts relating to it mainly on matter, the argument is, on the face of it, worth examination.
The Oxford Dictionary gives a long definition of fact-cthing assumed as basis for inference"; "thing certainly known to have occurred or be true". True is defined there as "in accordance with fact". How do these definitions fit in with the outlook of the man of science?

There can be surely no question that the now vast body of scientific workers regard their observations as facts, and also they have a high moral sense of obligation for their pronouncements. As the result of carefully devised experiment, results are obtained which become a basis for inference. These are published for criticism by fellow workers, and if no flaws or omissions are found in the experimental work, they are accepted as facts and form the basis of theories--even of rival theories, a choice between which is only possible when further facts are available. Theories must be altered to fit facts ; facts can never be adjusted to fit theories.

In more leisurely days, when a research was published after completion of the work, both facts and theories had been frequently tested during a year or more of investigation, and the final conclusions had a high degree of permanence. When work, however, such as that carried out in the Cavendish Labóratory, is of the greatest international interest, it is desirable to make the 
results of the experiments known immediately, it being well understood by colleagues that additional work is in hand. In consequence, there has been a certain amount of correction and withdrawalwhat some laymen have called impermanence of facts. This might perhaps have been avoided if publication had been withheld for two or three years, and only the final story told. But the loss would have far outweighed the gain ; the individual laboratories would not have been aware of what the others were doing, which experiments to repeat critically, which further developments to pursue or leave to another laboratory. Quick publication has enormously accelerated the rate of progress ; the withdrawal of a few errors has been a low price to pay.

Critics unfriendly to science say we 'assert': surely we have a right to do so. The orderly structure of chemistry, based on facts, has enabled us to prophecy with accuracy the existence as well as the chemical and physical properties of undiscovered elements. These were verified when the advancement in experimental technique made the discovery of a new element possible. It is true that the scheme of the elements as originally devised has been proved incomplete; for example, it made no provision for the group of rare gases, present in the air around us, discovered by Rayleigh and Ramsay : this is because for a long time the facts indicating their existence had been overlooked. But the fact $\longrightarrow$ minute difference in density between samples of nitrogen of different origin-once established, it was followed up until the reason for the difference was shown to be the presence in traces of another gas with very negative properties. Such facts have no impermanence, no relation to doctrinal system.

Another example may be quoted. The organic chemist had used facts to build up a molecular architecture, often of amazing complexity, for carbon compounds, including the natural substances of plants and animals. The chemist was convinced as to the accuracy of this architecture, for he had tested it in so many ways ; but it was none the less satisfactory to have these structures confirmed when the Braggs, father and son, developed the technique of X-ray analysis. This, at first confirmatory, has now gone past what the chemist can do, and has established new facts so that we can picture the structure of starch and cellulose, hair and horn.

These are pormanent facts, always being added to. The first theories are tentative; new facts strengthen or alter them, but they are always in a state of flux, for theories cannot be permanent though they may endure for a decade or many.

We cannot view the facts of science as impermanent. Doctrinal truths are in quite a different category ; their discussion is an individual matter, and no part of our task.

\section{A PHILOSOPHY OF PAIN AND FEAR}

Fears may be Liars

By Prof. John A. Ryle. Pp. 96. (London: George Allen and Unwin, Ltd., 1941.) 3s. 6d. net.

PROF. RYLE's book has, he tells us, been written both for believers and unbelievers to hearten and console men and women in times of trial and trouble. He assures them that pain and fear are natural phenomena; that there is no evidence that they are punishments for our misdeeds; that on the contrary they are conditions not only of the survival but also of the advance of life-without them, it seems, the higher species could not have evolved-and that, so far from being shelved and shunned and enveloped in an atmosphere of mystery, they should be subjected to study and research which show them to be not so very dreadful after all.

Take death, for example. Religion, Prof. Ryle points out, has made death more formidable than it is, terrifying men with the fears of hell and bribing them with the dubious joys of heaven.
In fact every death is the beginning of a "peaceful, dreamless night", a nothingness in which we cease to be. Prof. Ryle infers this view of death from the closeness of the mind-body relation. Sensations, emotions, feelings of pain and pleasure are all dependent on the integrity of the nervous system; at death the nervous system disintegrates and our sensational and emotional life, therefore, comes to an end. Possibly; possibly not.! The question whether death is the end raises an immense variety of issues and can be approached from a multitude of angles. Of these issues, those that fall within the province of physiology are a small minority ; of these angles, that of the medical man only one. For my part, I should have thought that the agnosticism of Socrates' argument-we do wrong to fear death, not because we know that nothing happens after it, but because we do not know whether what happens after (if anything) is better or worse than what happens to us when we are alive; it might just as well be betterwas at once more prudent and less dogmatic. 